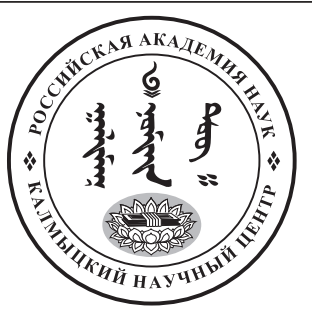

Published in the Russian Federation

Oriental Studies (Previous Name: Bulletin of the Kalmyk Institute

for Humanities of the Russian Academy of Sciences)

Has been issued as a journal since 2008

ISSN: 2619-0990; E-ISSN: 2619-1008

Vol. 13, Is. 6, pp. 1568-1578, 2020

DOI: $10.22162 / 2619-0990-2020-52-6-1568-1578$

Journal homepage: https://kigiran.elpub.ru

УДК 398.1

DOI: $10.22162 / 2619-0990-2020-52-6-1568-1578$

\title{
Семантика, генезис и аспекты бытования культовой лексики в традиционной культуре бурят
}

\author{
Элеонора Аллековна Неманова
}

${ }^{1}$ Восточно-Сибирский государственный институт культуры (д. 1, ул. Терешковой, 670031 УланУдэ, Российская Федерация) кандидат исторических наук, доцент

(iD) 0000-0002-5784-0161. E-mail: elnem@inbox.ru

\author{
(C) КалмНЦ РАН, 2020 \\ (C) Неманова Э. А., 2020
}

Аннотация. Введение. Одним из наиболее перспективных аспектов работы в исследованиях культовой традиции бурят является исследование понятий «культа» и «сакрального». Цель. Анализ проблемы применения категории «священного», разработанной европейской религиоведческой наукой, к лексическому материалу, связанному с категорией сакрального в традиционной культуре бурят. Mатериаль. Этимологические и историко-генетические исследования в области культовой традиции и шаманизма бурят. Результаты. Описание сферы применения понятия «сакрального» в бурятской культуре, а также семантический анализ необходимы во избежание неадекватного толкования и экстраполяций при его использовании. Представления, отмечающие корреляцию «священного» и «сверхъестественного», особенно в плане воздействия божеств / предков отражают дихотомию сакрального и профанного локуса, взаимодействие и коммуникацию которых следует признать основной канвой и сюжетом «религиозного» мышления бурят. В силу своей консервативности обрядовые термины содержат неоценимые свидетельства культурно-исторического прошлого, сохраняют ту ценную информацию, которая позволяет реконструировать этнографию прошлого народа, его социальную организации общества, духовной культуры, в том числе и культовой традиции.

Ключевые слова: иерофания, адорация, сакральность, культ, теофания, божество, душа, судьба

Для цитирования: Неманова Э. А. Семантика, генезис и аспекты бытования культовой лексики в традиционной культуре бурят // Oriental Studies. 2020. T. 13. № 6. С. 1568-1578. DOI: 10.22162/2619-0990-2020-52-6-1568-1578 
UDC 398.1

DOI: $10.22162 / 2619-0990-2020-52-6-1568-1578$

\title{
Cult Vocabulary in Buryat Traditional Culture: Semantics, Genesis, and Aspects of Functioning
}

Eleonora A. Nemanova ${ }^{1}$

${ }^{1}$ East-Siberian State Institute of Culture (1, Tereshkova St., Ulan-Ude 670031, Russian Federation) Cand. Sc. (History), Associate Professor

iD 0000-0002-5784-0161. E-mail: elnem@inbox.ru

(C) KalmSC RAS, 2020

(C) Nemanova E. A., 2020

\begin{abstract}
One of the most promising aspects of research into the cult tradition of the Buryats is the study of the concepts of 'cult' and 'sacred'. Goals. The paper aims to analyze the issue of applying the category of 'sacred' developed by European religious studies to the lexical material associated with the category of the sacred in the traditional culture of the Buryats on the basis of etymological and historical-genetic research. Results. Description of the scope of application of the concept of 'sacred' in Buryat culture, as well as semantic analysis are necessary to avoid inadequate interpretations and extrapolations while using respective lexemes. By virtue of their conservatism, ritual terms contain invaluable evidence of the cultural and historical perspectives, preserve the valuable information that allows us to reconstruct the ethnography of the past, its social structures, spiritual culture, including the cult tradition.

Keywords: hierophany, adoration, sacrality, the cult, theophany, deity, soul, destiny

For citation: Nemanova E. A. Cult Vocabulary in Buryat Traditional Culture: Semantics, Genesis, and Aspects of Functioning. Oriental Studies. 2020. Vol. 13(6): 1568-1578. (In Russ.). DOI: 10.22162/2619-0990-2020-52-6-1568-1578
\end{abstract}

\section{छ}

\section{Введение}

В религиоведческой науке «культ религиозный» (от лат. cultus — 'поклонение, почитание') как важнейший вид религиозной деятельности определяется в качестве «установленных традицией действий, путем которых достигается помощь сверхъестественных сил» [Религиозные верования 1993: 113]. Как отмечает О. М. Фрейденберг, «под культом принято понимать всю систему адорации, но, главным образом, обрядовый институт почитания и поклонения» [Фрейденберг 1998: 148]. Таким образом, основной чертой «культа» является адорация - обрядовое поклонение.

Однако что дефинирует его именно как «религиозный», т. е. как важнейший вид религиозной деятельности, учитывая, что существуют культы нерелигиозные? По замечанию О. М. Фрейденберг, «основной чертой «религиозного культа» являются его особая священность и сакрамент» [Фрейденберг 1998: 148]. В свою очередь, согласно построениям М. Элиаде, «любая религиозная форма в традиционном обществе имеет три основных структурных компонента: а) иерофания (букв. «проявление / явление священного»); б) мифологические, социальные и моральные представления, связанные с данный иерофанией; в) соответствующий индивидуально-психологический опыт» (цит. по: [Островский 1997: 19]). Ключевое в концепции М. Элиаде понятие «иерофания» трактуется как «манифестация сакрального в ментальном мире тех, для кого оно таковым является» [Элиаде 2000: 26].

В плане конкретизации данного понятия исследователь предложил понимать под соответствующими манифестациями явления и объекты (природные или рукотворные), 
непосредственно выявляющие сакральное (от лат. sacer, sacri 'священный, святой'). Понятие «иерофания» не содержит «никакого дополнительного значения, выражая лишь то, что заключено в нем этимологически - нечто священное, предстающее перед нами» [Элиаде 2000: 255].

Соответственно адорация обуславливается изначальной сакральностью персонажа, под «культом религиозным» следует понимать почитание тех или иных объектов (исторических и мифологических персонажей, их изображений, различных живых существ, предметов, элементов ландшафта и т. д.), которые рассматриваются в той или иной религиозной традиции как сакральные. Впрочем, здесь следует заметить, что, как считает Е. А. Торчинов, мера или степень «сакральности» (в рамках дихотомии «сакральное профанное») не является устойчивой [Торчинов 1998: 18-19]. По его мнению, мера сакральности обуславливается глубинными психологическими трансперсональными переживаниями, в том числе перинатально-архетипическими. Например, под ритуалом, область которого настолько близка с культом, что порой их трудно разграничить, следует понимать «совокупность определенных актов, имеющих сакральный смысл и направленных или на воспроизведение того или иного глубинного переживания, или на его символическую репрезентацию» [Торчинов 1998: 67]. И, наоборот, «утрата ритуалом связи с глубинным переживанием ведет к его формализму и утилитарности, соответственно к профанизации сакрального» [Торчинов 1998: 69].

Однако в связи с этим возникает проблема применения категории «священного», разработанной европейской религиоведческой наукой, относительно к традиционной культуре бурят. По нашему мнению, перенесение и применение данной категории в исследования по традиционному мировоззрению и верованиям вызывает определенные затруднения, но, как кажется, не лишено смысла. Поэтому важно конкретизировать сферу применения данного понятия в бурятской культуре, в связи с чем, во избежание неадекватного толкования и экстраполяций при его использовании, следует уделить внимание семантическому анализу лексического материала, связанного с категорией сакрального.

\section{Мүргэл}

В бурятском языке адорацию выражает термин мургэл, который в «Бурят-монгольско-русском словаре», составленном К. М. Черемисовым, переводится со следующими значениями:

1. 'поклонение, земной поклон';

2. 'молебен, религиозный обряд'; мургэлгэ 'поклонение' [БМРС 1951: 325].

По мнению И. М. Манжигеева, мургэл «общее название всех видов поклонения духам, в том числе земной поклон, обряд жертвоприношения» [Манжигеев 1978: 59]. Например, этим термином (мургэл или мургэжэ) обозначался свадебный обряд «кормления» невесткой онгонов (предков) семьи / рода жениха у предбайкальских бурят.

\section{Арюун}

Понятие «сакрального» выражает слово арюун 'священный, святой, негреховный' [Манжигеев 1978: 20]. Но оно также переводится и как 'чистый' (в халхаском ариун означает 'священный' и 'чистый'). В «Бурят-монгольско-русском словаре» термину арюун даются следующие определения:

1. 'чистый, ясный светлый, прозрачный' (о воде);

2. 'чистоплотный, опрятный, красивый';

3. 'чистый, честный, священный, святой’ [БМРС 1951: 68].

Показательно в связи с этим, что производным от арюун является термин арюулха, обозначающий обрядовое действо очищения огнем перед контактом с божествами / духами в ритуалах жертвоприношения или в обряде посвящения шамана. Ритуальное очищение заключалось в том, что перед основной частью жертвоприношения участник - мужчина рода - должен был очиститься путем обнесения себя огнем и окуривания можжевельником (арса), богородской травой (ая-ганга) или веткой пихты (жодоо). «...Запах священных растений выполнял важнейшую функцию преобразования „чужого“ в „свое“, наделяя земных людей сверхъестественными качествами и способностями» [Содномпилова 2020: 39].

Отметим в связи с этим, что обряд арюулха - очищения являлся константным элементом всех обрядов. Более того, по данным О. Н. Шаглановой, очищающее окуривание или обнесение огнем в этом ритуале дополнялось символическим омыванием (таримдаха) участников аршаном — водой 
из священного источника [Шагланова 2002 : 221]. «Во многих эпических произведениях и преданиях окуривание священными растениями является неотъемлемой частью процесса воскрешения мертвого героя, наряду с омыванием водой бессмертия» [Содномпилова 2020: 40].

Идея ритуальной чистоты выражалась в ряде запретов и ограничений для «чужих» в ритуальной деятельности социума. Так, шаманы («черные») могли участвовать (как члены рода) в обрядах тайлгана, но, имея «чужое» (xapu) yдxa, не могли проводить их или руководить ими. Безусловным был запрет на присутствие в этих обрядах женщин — «чужих» ${ }^{1}$. Обеспечение «ритуальной чистоты» также было связано с запретом на участие в тайлгане «загрязнившихся» / «осквернившихся» (бузардаха) и в обязательном «очищении» (арюулха) всех, кто допускался к участию в обряде, что отчетливо выявляет «нечистоту» человеческого / «профанного» локуса по отношению к миру сакрального.

«Символическое» поведение, формируемое на основании выделенных семантических рядов, конкретизирующих сферы «сакрального» и «нечистого», реализуется преимущественно в ритуальной практике. Его «стратегия», например, выявляется в локативном коде обрядов, где важное значение играет пространственная оппозиция: правое левое (запад $\sim$ восток или юг север). Но, главным образом, «стратегия» символического поведения находит выражение в концепции ритуальной чистоты (перед и во время контакта с почитаемыми духами и божествами), являющейся парадигматической для традиционной обрядности бурят, что особенно показательно в контексте семантической корреляции «священного» и «чистого».

Подобные этические представления порождали многочисленные запреты, последствия которых в силу их соблюдения

\footnotetext{
${ }^{1}$ Категория «нечистого» в бурятской культуре включала в себя, главным образом, женщин в период беременности или менструаций, причем роженица уравнивалась с покойником, а также мужчин, соприкасавшихся с ними, и др. Например, роженица могла привести к сокращению «сакральности», из-за чего она в течение трех дней после родов не могла перешагивать порог юрты, чтобы не уничтожить «благодать дома» (гэрын хэшэг) [Нацов 1995: 35].
}

или, наоборот, нарушения, подчеркивают их архаический магический контекст. Нарушение их, главным образом, ритуальной чистоты, рассматривалось как сээр - грех и приводило к неминуемому наказанию со стороны божеств. Как отметил Т. М. Михайлов, у бурят «принцип „сээртэй“"» или «будет плохо впоследствии, в потомстве» действовал эффективно» [Михайлов 1987: 150].

\section{Онго(н)}

Другой термин, связанный с категорией сакрального в бурятской культуре, го(н). В «религиозном» (культовом) аспекте онгон - это, во-первых, почитаемый ,дух“ предка, во-вторых, его изображение, являющееся вместилищем данного ,духа“» [Жуковская 1994: 255]. В монгольской традиции онгон, по определению Б. Я. Владимирцова, понимается как: 1) «душа» — sünesü sülde почитаемого предка; 2) aүula-yin ejed «владыки гор»; 3) sütüge — изображения

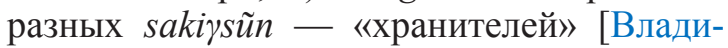
мирцов 1926: 25].

В бурятской традиции онгонь - особый класс божеств-покровителей, хотя и очень разнородный по своему составу. Так, согласно И. М. Манжигееву, онгон - это:

1) «дух-хозяин» отдельных участков земли и воды;

2) дух предка;

3) душа / дух умершего шамана, воина, охотника, отличившегося при жизни и т. д.;

4) душа трагически умершего в молодости человека; какой-либо почитаемый дух или божество, по отношению к которому существует табу, запрещающее произносить его собственное имя вслух, а также образные персонификации различных видов производственной деятельности, атмосферных явлений и т. д. [Манжигеев 1978: 64-65].

В силу гетерогенности персонажей, составляющих данную категорию божеств, существовали семейные онгоны, производственные онгоны, онгоны особых шаманских «поколений» (их изображения выступали своеобразным маркером-символом «шаманской наследственности»), родовые онгоны, улусно-общинные и даже, как отметил С. П. Балдаев, «племенные онгонь булагатов, хонгодоров, хоринцев и эхиритов» [Балдаев 1970: 10-13]. В целом термин онго(н) имеет значения 'чистый, священный, 
первоначальный, девственный' [Жуковская 1994: 255].

В связи с этим лексико-семантическое поле данного термина в бурятском языке формируют следующие значения: 1) изображение какого-либо божества; дух, гений, идол; 2) священный [БМРС 1951: 369]. В монгольском языке (халхаский диалект): 1) гений-хранитель места (местности); 1) «дух» предка; 3) чистый, священный [Санжеев 1947: 156]. Таким образом, термин онго(н), обозначая сверхъестественного персонажа или его изображение, трактуемое как «вместилище» или замещающий символ божества или «духа» предка, одновременно является и обозначением «священного» в традиции. В плане обозначения «священного» показательны следующие примеры употребления этого термина, которые приводит И. М. Манжигеев: онгон сагаан үһэн досл. 'священные седины волос' - «эпитет древнебурятского патриархального культа предков»; онго нуур 'священное озеро'; онго хирбээ дайда досл. 'священные девственные просторы’ [Манжигеев 1978: 64].

Таким образом, с одной стороны, понятие «священного» в бурятском языке образует единое семантическое поле с понятием «чистый», имеющим ритуализированный контекст. В плане соответствующей семантической корреляции, особенно в связи с полисемантичностью термина онгон, весьма репрезентативным представляется материал о юһэнгуут 'ax - 9 помощниках шамана в обряде шанар (посвящение шамана) у хорибурят, символизирующих 9 (юһэн) сыновей Неба. «Кандидаты в юһэнгууты, выбираемые из улусной молодежи, должны были быть беспорочными, нравственно и физически здоровыми и чистыми. После тщательного отбора избранные проходили ритуальное очищение, затем их одевали во все белое (чистое) и шаман вселял в них «души» (онго) детей неба. После этого они превращались в живых онгонов и помогали шаману в проведении обряда» (курсив мой. - Э. Н.) [Дугаров 1991: 172].

С другой стороны, семантика термина онго $(H)$, обусловленная набором его лексических значений, позволяет считать, что категория «священного» в бурятской культуре в определенной мере сближается с теологической концепцией сакральности как принадлежности и причастности к идее бога [Религиозные верования 1995: 183], что, очевидно, не отрицает и семантика термина арюун.

В целом в культовом («религиозном») аспекте понятие онгона находится в тесной корреляции с категорией «сверхъестественного» ${ }^{2}$. Здесь следует особо подчеркнуть, что в архаическом социуме (шире - в традиционном, сохранявшим многие черты архаичного) «при невозможности абстрактного обобщения и при необходимости обобщения образного бог, principium volens, представляется конкретной личностью. Образ этот не плоский, а разносторонний, не исключающий противоречивости. Отсюда полнокровность богов, их неподверженность какой-то идеализации и не сводимости к абстрактным функциям» [Дьяконов 1990: 105]; более того, божества, обладавшие, таким образом, волей и, тем самым, разумом, представлялись «вполне телесно» [Дьяконов 1990: 63-64].

По замечанию Т. М. Михайлова, «культовая деятельность бурят-шаманистов никогда не была абстрактной. Почитаемые объекты или силы, от которых зависело якобы благополучие человека, мыслились конкретно - в образе тэнгэри, хана, эжина, заяана» [Михайлов 1987: 65]. При этом каждый из почитаемых сверхъестественных персонажей обладал собственной достаточно проработанной «биографией», отраженной как в мифологических преданиях, быличках, так и в обрядовых текстах — в «призываниях» (см.: [Неманова 2018: 101]).

В свою очередь реальность локуса сверхъестественного, как и реальность его ощущения, реализовывалась в традиционном мировоззрении бурят в его конкретной топонимической привязке. Таким образом, сфера сверхъестественного в традиционном мировоззрении бурят не имела отвлеченного экстраполирующего понятия, а всегда

${ }^{2}$ Например, священное озеро онго нуур, по И. М. Манжигееву, это: «1) почитаемое шаманистами озеро, олицетворяющее дух местного шамана (шаманки), имевшего по преданию, какое-либо отношение к данному озеру; 2) озеро, в котором шаманисты купали домашних животных по случаю какого-либо эпизоотического заболевания» [Манжигеев 1978: 64]. Сверхъестественные возможности последнего и вытекающая из этого его «священность», маркируемое термином онго, обуславливается тем, что это озеро является местопребыванием особого «духа-хозяина» - онгона. 
связывалась с конкретным образом - «духом» или божеством (см. например: [Бакаева и др. 2016]). Соответственно, иерофания как «манифестация священного» в религиозной традиции бурят (в ритуальной практике), конкретизируется более как теофания («богоявление»).

В этой связи в контексте соответствующих дефиниций категории сакрального в бурятской культуре наиболее репрезентативным представляется почитание онгонов - изображений (иконических, аниконических, статуарных, животных) почитаемых персонажей, также обозначаемых соответствующим термином. «Священность (онго) обуславливалась тем, что они выступали 'вместилищами' соответствующего почитаемого божества или предка или, как считалось, в них присутствует его дух - онго, благодаря чему обеспечивалось 'сверхъестественное' благополучие их владельцев» [Жуковская 1994: 255]. Животные онгоны у бурят и монголов аналогичны, как уже отмечалось в исследовательской литературе, ьлыькам / ызыххам — «посвященным» различным божествам домашним животным у тюркоязычных народов, название которых переводится как 'священный, чистый'.

Таким образом, онгон - это не только сверхъестественный персонаж - божество / предок или его «изображение-вместилище», но и активная внематериальная субстанция, изофункциональная почитаемому божеству / предку, и в силу этого ассоциируемая с ним. Именно она, по нашему мнению, обуславливает «сверхъестественные» возможности онгонов, ее «аккумулирующих», благодаря чему собственно и проявляется активность сверхъестественного персонажа, опосредованная различными материальными формами адорации.

Наряду с этим в монгольской традиции онгон — это sünesü sülde почитаемого предка. Аналогичный феномен у бурят hүнэһэ hүлдэ, или «хорошая душа» (haйн hүнэһэн) - одна из трех душ человека, «которая после смерти своего обладателя поднимается на небо и возвращается обратно в виде «духа» предка» [Манжигеев 1978: 96].

\section{Сүлдэ}

Для обозначения феномена сүлдэ традиционно использовались анимистические категории «дух», «душа» и т. д., что, по замечанию Т. Д. Скрынниковой, стало общим местом в исследованиях [Скрынникова 1997б: 149-150]. Впервые их использовал Д. Банзаров, употребивший термин «бессмертная душа» [Банзаров 1997: 46]. По его мнению, «первоначальное простое почтение к предкам подверглось искажению и породило онгонов. Так называют монголы души умерших людей, сделавшиеся предметом уважения или страха народного» [Банзаров 1997: 47].

В монгольской традиции представления о «душе», будь то в естественном или символическом языке, не одинаковы для различных ситуаций. Так, в исследовательской литературе с понятием «души» соотносятся термины сүнэсүн / Һүнэһүн и амин, связанные с витальностью человека (их семантическими коррелятами выступают кровь и дыхание), а также сүлдэ / һүлдэ. По мнению Т. Д. Скрынниковой, «использование термина «душа» в отношении $c ү л д э^{3}$ неадекватно реальности, поскольку в данном

3 Наиболее репрезентативным, по замечанию Т. Д. Скрынниковой, является материал по «сүлдэ» (халх. сүлд, бур. Һүлдэ). В исследовательской литературе сүлдэ / һүлдэ традиционно дефинировалась как «жизненная сила» человека [Манжигеев 1978: 94], «жизненность» или «душа-судьба» [Галданова 1987: 59-73]. Например, по определению В. А. Михайлова, «сулде - первоначальная причина; та сила, от которой зависит существование силы в вещах» [Михайлов 1996: 62]. При этом исследователи почти единодушно дифференцировали ее от сүнэсү(н) / Һүнэһүн — «души»-«двойника» человека. «Исчезновение сулдэ, как полагали, не вызывает смерти сразу. Без души человек еще достаточно долго может влачить существование, но не жить в полном смысле этого слова. Долгое отсутствие сулдэ приводит ... к уничтожению жизненности» [Галданова 1987: 71]. По замечанию С. Ю Неклюдова, «душа», никогда не оставляющая человека (= «душа-тень», «душа-двойник») — это «телесная душа», которая считается «плохой» («дурной»); она продолжает жить в трупе (или подле него до его разложения), после чего исчезает или становится злокозненным духом [Неклюдов 1994б: 174]. Противопоставляемая же ей субстанция сүлдэ — «бессмертная душа» или «хорошая душа» - одна из двух / трех «душ» человека (наряду с сүнэсү), которая довольно легко покидает тело (во время сна, болезни, у шамана - во время камлания), отлетает после смерти и становится духом или возвращается на небо [Неклюдов 1994б: 174] (становится, по И. М. Манжигееву, һүнэһэ һүлдэ - см. выше). 
случае речь идет о сакральности не только предка, но и рода, а не о витальности человека» [Скрынникова 1997б: 152].

В этой связи следует отметить, что нарицательным обозначением всех аналогичных феноменов, связанных с «сакральностью», стал австронезийский термин мана, введенный в широкий обиход Р. Кодрингтоном и получивший, по выражению Е. С. Новик, «права гражданства в этнографической литературе» [Новик 2004: 138]. Эта сакральная субстанция, выступающая, по мнению исследователей, в качестве важнейшей категории «сверхъестественного», имеет следующие значения: незримая сила, мощь, могущество; сила влияния, воздействия на кого-либо; удача; необыкновенное событие, чудо (в христианском смысле) - чудо как проявление мaныl $^{4}$; сверхъестественное событие или действие; сверхъестественная сила; влияние сверхъестественного [Элиаде 2000: 25].

В трактовке С. Ю. Неклюдова она представляет собой «разумное начало в человеке», противостоящее нравственной порче, и, очевидно, в качестве такового, выступающее своеобразным ангелом-хранителем [Неклюдов 1994а: 375]. Однако более прозрачна в этом плане ее связь с «судьбой» человека, в связи с чем феномен, обозначаемый как сүлдэ / hүлдэ, также маркируется термином дзаяа (бур. заяа) - «судьба» [Неклюдов 1994a: 375], при том что в монгольской традиции известен феномен дзаяа сглдэ. Таким образом, «избранные» транслируют воздействие сакральной субстанции Неба или высших небесных божеств, что согласуется с медиативной функцией предков, «категория сверхъестественного оформляется в процессе развития мифологического сознания, включающего отделение человека от природы, приписывание ей враждебности по отношению к нему и уход первопредка из физического мира в мир метафизический» [Плахова 2019: 132].

Не в меньшей степени «генетический» мотив «получения свыше» характерен для

\footnotetext{
${ }^{4}$ Мана, согласно верованиям меланезийцев и полинезийцев, - это некая магическая сила, устойчиво связываемая со светом или жаром и имеющая устойчивое значение «сверхъестественная сила, потенция» [Петрухин, Полинская 1994: 166-167].
}

«сакральности, присущей всем», которая дается с рождением и затем обуславливает жизнь / судьбу (дзаяа / заяа) человека: дзаяа дается Небом (имеется в виду субстанция, равнозначная сүлдэ); у высших богов испрашивают сүлдэ детей, например, в преданиях, у Сагаан Убгена, Эсэгэ Малаана или у Хүхэ Мүнхэ тэнгри; в ритуальной традиции предбайкальских бурят - у Буха-нойона и его супруги Будан-хатун (в этом функциональном аспекте божеств выявляется связь сүлдэ с мотивом оплодотворения и чадородия (см.: [Содномпилова, Неманова 2019]).

Исходя из сопоставительного анализа употребления этих терминов, можно выде-

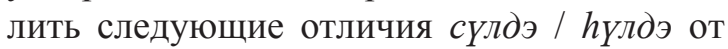
сүнесүн / Һүнэһүн и амин:

1) воплощение в материальных объектах, почитаемых в качестве «священных» (в дереве, стреле, онгонах, знамени и т. д.);

2) представления о сакральной субстанции «избранных», наделенных особой исключительностью - правителей, вождей, богатырей, вообще талантливых людей;

3) семантическая связь с сакральным «центром» мира [Галданова 1987: 68; Скрынникова 1997б: 140-189; Скрынникова 1997а: 11].

Именно поэтому «сверхъестественные» возможности «культовых предметов типа онгонов» влиять на благополучие их владельцев или социума, выполнять охранительные функции и т. д., обусловлены не столько благодаря тому, что они являются воплощением или вместилищем духов-покровителей, сколько благодаря воплощению в них сакральной субстанции предка [Скрынникова 1997б: 99]. Именно благодаря «аккумуляции» данной субстанции в различных материальных «иерофанических» объектах и предметах, обеспечивается их сверхъестественные возможности, соответственно, «священность» последних, благодаря чему обуславливается комплекс адораций, связанных с ними (культ онгонов, культ буудалов, культ «священных» гор, культ священных деревьев и т. д.).

Вместе с тем этот полисемантичный феномен можно соотнести с отмечаемой М. Элиаде «субстанцией» или «энергией» «высших» богов, использовавших ее в процессе творения и тратящих ее для поддер- 
жания мира и обеспечения его изобилия [Элиаде 2002: 91]. В этом аспекте особенно показательна креационная семантика термина дзаяа / заяа, поскольку, помимо маркировки «судьбы» (жизни) человека и субстанции, ее обуславливающей, дзаяа / заяа также имеет значения 'творение, созидание' / ‘творец, создатель'. Возможно, что креативный момент в древности включался и в семантическое поле термина онгон, так как его форма онгоруу, рудиментно сохранившаяся в якутском языке наряду с онгоcyy 'предназначение' (см. выше), является синонимом слова aйblbl с общим значением 'созидание, творение', а в форме онгороочуу соответствует айаaчblbl 'творец, создатель' [Дашиева 2001: 121].

Касаясь воздействия сакральной субстанции «извне», также хотелось бы обратиться к феномену «благодати» или «счастья» (хэшэг, хутаг / хутуг, даллга / даланza), призываемым в обрядах жертвоприношения ${ }^{5}$. Функционально они неразрывно связаны с отмечавшейся выше «сакральностью, присущей всем» - сглдэ / дзая, обуславливающей рождение человека, а затем и его жизнь (судьбу). Последняя, периодически как бы «сокращаясь», нуждается в регулярном ритуальном «восполнении» за счет «благодати» / «счастья», испрашиваемых у божеств в обрядах общественного цикла.

В свою очередь эти представления, отмечающие корреляцию «священного» и «сверхъестественного», особенно в плане воздействия сакральности божеств / предков «извне» и циркуляции сүлдэ человека между космологическими уровнями, наиболее прозрачно отражают дихотомию нашего / человеческого (профанного) локуса и иного / сверхъестественного (сакрального), взаимодействие и коммуникацию которых следует признать основной канвой и сюжетом «религиозного» мышления бурят.

${ }^{5}$ В бурятской традиции «благодать» может связываться (в плане воздействия) как с харизмой умерших предков (или с ними соотнесенных «избранных» - вождей, нойонов, кузнецов и т. д.), сохраняющей воздействие после смерти своего суверена, так и напрямую с «субстанциональным» проявлением (теофанией) верховных божеств, рудименты адорации которых охранялись вплоть до рубежа XIX-XX вв.

\section{Выводы}

Отмечая соотнесенность в мифо-ритуальной традиции бурят категорий «сверхъестественного», формы проявления которого обуславливались субстанцией сүлдэ или онго и «сакрального», нельзя не подчеркнуть, что дефиниция последнего явно не исчерпывается соответствующей корреляцией. Как мы отметили выше, «сверхъестественное» не обязательно является «священным», притом, что, если ориентироваться на определение Е. А. Торчинова, адорацию обуславливает именно сакральность персонажа. Соответственно, в дифференциации обрядов можно, с одной стороны, видеть реализацию пресловутой меры / степени сакральности, которая находится в тесной корреляции с бинарностью пантеона: светлые (сагаан) добрые божества темные (хара) злые божества; «белые» и «черные» шаманы. Следовательно, в плане конкретизации сферы сакрального в традиционной бурятской культуре мы вновь возвращаемся к семантической соотнесенности «священного» и «чистого», цветовым коррелятом которого выступает белый цвет (сагаан), о сакральности которого в бурятской (монгольской) мифо-ритуальной традиции написано очень много. Отсюда обряды поклонения / почитания, а не «умилостивления», в чем, как представляется, и заключен смысл адорации / религиозного культа, совершались белым / чистым, т. е. священным персонажам. В этой связи с этим хотелось бы подчеркнуть, что всякая религиозная форма (адорации) предполагает «связь» между людьми и сверхъестественными силами (божествами), что совпадает с самым общим и древнейшим смыслом термина «религия», производным от лат. термина religo 'связывать' [Гумилев 1994: 249].

В целом анализ специфических обрядовых терминов в бурятском языке показывает, что большинство из них своим генезисом восходят к тюркской сакральной лексике или общему тюрко-монгольскому (шире - алтайскому) лексическому фонду, что указывает на важную роль древнего и средневекового тюркоязычного компонента в этногенезе и этнической истории современных и исторических монголоязычных народов. 


\section{Литература}

Бакаева и др. 2016 - Трансграничная культура: очерки сравнительно-сопоставительного исследования традиций западных монголов и калмыков / Э. П. Бакаева, К. В. Орлова, Д. Н. Музраева, Т. И. Шараева, Н. В. Балинова, И. А. Хомякова, С. В. Мирзаева. Элиста: КалмНЦ РАН, 2016. 456 с.

Балдаев 1970 - Балдаев С. П. Родословные предания и легенды бурят. Ч. 1. Булагаты и эхириты. Улан-Удэ: Бурятск. кн. изд-во, 1970. $362 \mathrm{c}$.

Банзаров 1997 - Банзаров Д. Собрание сочинений. Изд. 2-е дополненное. Улан-Удэ: Издво БНЦ СО РАН, 1997. 240 с.

БМРС 1951 - Бурят-монгольско-русский словарь = Бурят-монгол-ород словарь / сост. К. М. Черемисов; под ред. Ц. Б. Цыдендамбаева. М.: Гос. изд-во иностранных и национальных словарей, 1951. 852 с.

Владимирцов 1926 - Владимириов Б. Я. Образцы монгольской народной словесности (Cеверо-Западная Монголия). Л.: Ин-т живых вост. яз., 1926. 202 с.

Галданова 1987 - Галданова Г. Р. Доламаистские верования бурят. Новосибирск: Наука, 1987. $113 \mathrm{c}$.

Гумилев 1994 - Гумилев Л. Н. Сочинения. Конец и вновь начало. М.: ДИ-ДИК, 1994. $541 \mathrm{c}$.

Дашиева 2001 - Дашиева Н. Б. Календарь в традиционной культуре бурят (опыт историко-этнографического и культурно-генетического исследования). М., Улан-Удэ: ИПК ВСГАКИ, 2001. 299 с.

Дугаров 1991 - Дугаров Д. С. Исторические корни белого шаманства (на материале обрядового фольклора бурят). М.: Наука, 1991. $300 \mathrm{c}$.

Дьяконов 1990 - Дьяконов И. М. Архаические мифы Востока и Запада. М.: Наука, 1990. 247 c.

Жуковская 1994 - Жуковская Н. Л. Онгоны // Мифы народов мира. Т. 2. М.: Сов. энциклопедия, 1994. С. 255-266.

Манжигеев 1978 - Манжигеев И. А. Бурятские шаманистические и дошаманистические термины. М.: Наука, 1978. 128 с.

Михайлов 1987 - Михайлов Т. М. Бурятский шаманизм: история, структура, социальные функции. Новосибирск: Наука, СО, 1987. $290 \mathrm{c.}$

Михайлов 1996 - Михайлов В. А. Религиозная мифология. Улан-Удэ: Соел культура, 1996. $111 \mathrm{c}$.
Нацов 1995 - Нацуов Г. Д. Материалы по истории и культуре бурят. Улан-Удэ: БНЦ СО PAH, 1995. $156 \mathrm{c}$.

Неклюдов 1994а - Неклюдов С. Ю. Дзаяачи // Мифы народов мира. Т. 1. М.: Сов. энциклопедия, 1994. С. 375.

Неклюдов 19946 - Неклюдов С. Ю. Монгольских народов мифология // Мифы народов мира. Т. 2. М.: Сов. энциклопедия, 1994. C. $170-174$.

Неманова 2018 - Неманова Э. А. Сутра «Белый старец (Сагаан үбгэн)»: мифологические основы культа // Известия Иркутского государственного университета. Сер.: Геоархеология. Этнология. Антропология. 2018. T. 25. C. 101-111.

Новик $2004-$ Новик E. C. Обряд и фольклор в сибирском шаманизме: Опыт сопоставления структур. М.: Вост. лит., 2004. 304 с.

Островский 1997 - Островский А. Б. Мифология и верования нивхов. СПб.: Петербургское Востоковедение, 1997. 2782 с.

Петрухин, Полинская 1994 - Петрухин В. Я., Полинская М. С. О категории «сверхъестественного» в первобытной культуре // Историко-этнографические исследования по фольклору: Сборник статей памяти С. А. Токарева. М.: Вост. лит., 1994. 276 с.

Плахова 2019 - Плахова О. А. Сущность мифологического сознания как интегративного элемента народного художественного сознания // Балтийский гуманитарный журнал. 2019. T. 8. № 1 (26). С. 130-132.

Религиозные верования 1993 - Религиозные верования. Свод этнографических понятий и терминов. М.: Наука, 1993. 239 с.

Санжеев 1947 - Санжеев Г. Д. Первоначальные монгольские тексты. М.: Изд-во и стеклогр. МИВ, 1947. 107 с.

Скрынникова 1997а - Скрынникова Т. Д. Традиционное мировоззрение бурят и шаманизм // Методологические и теоретические аспекты духовной культуры Востока. Вып. 2. Улан-Удэ, 1997. С. 11-19.

Скрынникова $1997 б$ - Скрынникова Т. Д. Харизма и власть в эпоху Чингис-хана. М.: Вост. лит., 1997. 214 с.

Содномпилова 2020 - Содномпилова М. М. Мир запахов и ольфакторная коммуникация в традиции тюрко-монгольских народов Внутренней Азии // Известия Иркутского государственного университета. Сер.: Геоархеология. Этнология. Антропология. 2020. T. 32. C. $37-47$. 
Содномпилова, Неманова 2019 - Содномпи лова М. М., Неманова Э. А. Представления о зарождении жизни и ее качестве в мировоззрении монгольских народов // Монголоведение (Монгол судлал). 2019. № 11 (3). C. 465-478. DOI: 10.22162/2500-1523-2019$3-465-478$

Торчинов 1998 - Торчинов E. А. Религии мира: опыт запредельного. СПб.: Центр «Петербургское Востоковедение», 1998. 384 с.

Фрейденберг 1998 - Фрейденберг О. М. Миф и литература древности. М.: Вост. лит., 1998. $800 \mathrm{c}$.

\section{References}

Bakaeva E. P. et al. Cross-Border Culture: Essays on the Comparative Study of Traditions of the Western Mongols and Kalmyks. Elista: Kalmyk Scientific Center (RAS), 2016. 456 p. (In Russ.)

Baldaev S. P. Genealogical Traditions and Legends of the Buryats. Vol. 1: The Bulagat and Ekhirit. Ulan-Ude: Buryat Book Publ, 1970. 362 p. (In Russ.)

Banzarov D. Collected Works. Ulan-Ude: Buryat Scientific Center (Sib. Branch of RAS), 1997. 240 p. (In Russ.)

Bromley Yu. V. et al. (eds.) Religious Beliefs: Collected Ethnographic Concepts and Terms. Moscow: Nauka, 1993. 239 p. (In Russ.)

Cheremisov K. M. (comp.), Tsydendambaev Ts. B. (ed.) Buryat Mongolian-Russian Dictionary. Moscow: State Publ. House of Foreign and National Dictionaries, 1951. 852 p. (In Bur. and Russ.)

Dashieva N. B. Calendar In Buryat Traditional Culture: A Historical-Ethnographic and Cultural-Genetic Study. Moscow, Ulan-Ude: East Siberian State Academy of Culture and Arts, 2001. 299 p. (In Russ.)

Dugarov D. S. Historical Roots of White Shamanism: A Case Study of Buryat Ritual Folklore. Moscow: Nauka, 1991. 300 p. (In Russ.)

Dyakonov I. M. Archaic Myths of the East and West. Moscow: Nauka, 1990. 247 p. (In Russ.)

Eliade M. A History of Religious Ideas: From Gautama Buddha to the Triumph of Christianity. Moscow: Criterion, 2002. 512 p. (In Russ.)

Eliade M. Selected Works: The Myth of the Eternal Return, Images and Symbols, The Sacred and the Profane. Moscow: Ladomir, 2000. 414 p. (In Russ.)
Шагланова 2002 - Шагланова О. М. Общесельский тайлган у тункинских бурят // Мир Центральной Азии. Т. 1. Археология и этнология. Улан-Удэ: Изд-во БНЦ СО РАН, 2002. C. 217-223.

Элиаде 2000 - Элиаде М. Избранные сочинения: Миф о вечном возвращении; Образы и символы; Священное и мирское. М.: Ладомир, 2000. $414 \mathrm{c.}$

Элиаде 2002 - Элиаде М. История веры и религиозных идей. От Гаутамы Будды до триумфа христианства. М.: Критерион, 2002. $512 \mathrm{c}$.

Freydenberg O. M. Myth and Literature of Ancient Times. Moscow: Vostochnaya Literatura, 1998. 800 p. (In Russ.)

Galdanova G. R. Pre-Lamaist Beliefs of the Buryats. Novosibirsk: Nauka, 1987. 113 p. (In Russ.)

Gumilev L. N. Essays. An End and a New Beginning. Moscow: DI-DIK, 1994. 541 p. (In Russ.)

Manzhigeev I. A. Buryat Shamanistic and PreShamanistic Terms. Moscow: Nauka, 1978. 128 p. (In Russ.)

Mikhaylov T. M. Buryat Shamanism: History, Structure, Social Functions. Novosibirsk: Nauka, 1987. 290 p. (In Russ.)

Mikhaylov V. A. Religious Mythology. Ulan-Ude: Soel-Kultura, 1996. 111 p. (In Russ.)

Natsov G. D. The Buryats: Materials on History and Culture. Ulan-Ude: Buryat Scientific Center (Sib. Branch of RAS), 1995. 156 p. (In Russ.)

Neklyudov S. Yu. Dzayaachi. In: Myths of the World. Vol. 1. Moscow: Sovetskaya Entsiklopediya, 1994. P. 375. (In Russ.)

Neklyudov S. Yu. Mythologies of Mongolic peoples. In: Myths of the World. Vol. 2. Moscow: Sovetskaya Entsiklopediya, 1994. Pp. 170-174. (In Russ.)

Nemanova E. A. Sutra of the White Elder (Sagaan Übgen): mythological bases of the cult. Bulletin of the Irkutsk State University. Geoarchaeology, Ethnology, and Anthropology Series. 2018. Vol. 25. Pp. 101-111. (In Russ.)

Novik E. S. Ritual and Folklore in Siberian Shamanism: A Comparative Insight into Essential Structures. Moscow: Vostochnaya Literatura, 2004. 304 p. (In Russ.)

Ostrovskiy A. B. The Nivkh People: Mythology and Beliefs. St. Petersburg: Peterburgskoe Vostokovedenie, 1997. 2782 p. (In Russ.)

Petrukhin V. Ya., Polinskaya M. S. Category of the 'supernatural' in primitive cultures revisited. 
In: Historical and Ethnographic Studies of Folklore. Collected Papers Commemorating S. A. Tokarev. Moscow: Vostochnaya Literatura, 1994. 276 p. (In Russ.)

Plakhova O. A. The essence of mythological consciousness as an integrative component of folklore consciousness. Baltic Humanitarian Journal. 2019. Vol. 8. No. 1(26). Pp. 130-132. (In Russ.)

Sanzheev G. D. Earliest Mongolian Texts. Moscow: Moscow Institute of Oriental Studies, 1947. 107 p. (In Russ.)

Shaglanova O. M. Taylgan of Tunka Buryats. In: The World of Central Asia. Vol. 1: Archaeology and Ethnology. Ulan-Ude, 2002. Pp. 217-223. (In Russ.)

Skrynnikova T. D. Charisma and Power in the Era of Genghis Khan. Moscow: Vostochnaya Literatura, 1997. 214 p. (In Russ.)

Skrynnikova T. D. Traditional worldviews of Buryats and shamanism. In: Spiritual Culture of the Orient. Methodological and Theoretical Aspects. Vol. 2. Ulan-Ude, 1997. Pp. 11-19. (In Russ.)
Sodnompilova M. M. World of smells and olfactory communication in the tradition of the TurkicMongolian peoples of Inner Asia. Bulletin of the Irkutsk State University. Geoarchaeology, Ethnology, and Anthropology Series. 2020. Vol. 32. Pp. 37-47. (In Russ.)

Sodnompilova M. M., Nemanova E. A. Worldview of Mongolic peoples: representations of the beginnings of human life and its prospective quality. Mongolian Studies. 2019. Vol. 11. No. 3. Pp. 465-478. (In Russ.) DOI: 10.22162/25001523-2019-3-465-478

Torchinov E. A. Religions of the World: Experience of the Transcendence. St. Petersburg: Peterburgskoe Vostokovedenie, 1998. 384 p. (In Russ.)

Vladimirtsov B. Ya. Images of Mongolian Folklore: Northwestern Mongolia. Leningrad: Institute of Living Oriental Languages, 1926. 202 p. (In Russ.)

Zhukovskaya N. L. Ongons. In: Myths of the World. Vol. 2. Moscow: Sovetskaya Entsiklopediya, 1994. Pp. 255-266. (In Russ.) 